described. This approach makes the text eminently readable; many references are listed but they do not interfere with smooth reading of the subject matter.

In each chapter the material has been presented from a very personal viewpoint. Authors have been chosen because of their work in the field and in many cases this work is the nucleus of each chapter. Professor Beling has based his chapter on his own results of oestriol excretion in normal and diabetic pregnancies. On the other hand Professor Goldzieher has contributed a review article on polycystic ovarian disease, and the editors have given a wide view of advances in infertility. The material presented is sometimes controversial and must be regarded as stimulating rather than as a definitive review of recent advances. For example; the pathological lesions of renal cortical necrosis, pituitary and adrenal apoplexy and eclamptic liver are all reputed to be due to the generalized Schwartzman reaction in pregnancy. The chapters on gynaecological cancer are dogmatic but produce figures from the authors' practice which make the contributions most acceptable.

The book can be recommended for all specialists in obstetrics and gynaecology. Its value is established before it is 6 months old and it is already being recommended in reading lists compiled by senior members of the speciality for their postgraduate pupils.

\section{Milestones in Midwifery}

By Walter Radcliffe. Pp. 110 illustrated. Bristol: John Wright. 1967. 25s.

In day-to-day practice we may, in the flurry of current achievements, fail to remember the tremendous debt we owe to our predecessors. It is, therefore, salutory to be reminded of this debt for, in this book, the author has outlined the history of midwifery from the Hippocratic era, through Roman times and the Middle Ages (with the serious study of human anatomy by Renaissance artists) to the laying down of the foundations of modern obstetric practice. In a final chapter, antenatal care, $\mathrm{X}$-ray diagnosis, Caesarean section, blood transfusion and antibiotics are introduced.

Throughout the book the author has managed to give a picture of the personalities named and has conveyed well the atmosphere obtaining of the times during which these men and women worked. Selected excerpts from their writings are included in each chapter and there are numerous illustrations and references in the book.

Here, then, for a very moderate sum, is a book of the history of midwifery which any reader who has interest in the current practice in midwifery would do well to read. Comprehensive enough for the average reader, this book is highly recommended either for individual or hospital library purchase.

\section{Individuality in Pain and Suffering}

By Asenath Petrie. Pp. xvii +153 illustrated. Chicago and London: University of Chicago Press. 1968. $\$ 5.00$. 45s.

The author, a psychologist, is concerned with the way in which sensory stimulation is treated so as to result in individual differences in perception. It is supposed that for a given amount of sensory stimulation some individuals will have a more intense or greater perceptual experience than others. For example lesions of the same size may give rise to larger or smaller experiences of pain from person to person. Similarly sensory deprivation may be better tolerated by those who extract more from the minutiae of stimulation than by those who are unresponsive to them. Direct measurement of experience is impossible but the author has developed a procedure to assess the presence of 'augmentation' or 'reduction'.

One hand is placed on a standard-sized wooden block.
The other then moves along a tapered block until a judgement of equivalent sizes is obtained. The first hand is next stimulated by rubbing to produce tactile satiation. Judgements of equivalent size are then made again at fixed times as originally. Changes from the baseline estimate of size give a measure of the individual's tendency to augment or reduce the effects of sensory stimulation.

Doctor Petrie produces evidence that 'augmenters' and 'reducers' do differ as postulated above in respect of pain and sensory deprivation. One study has failed to confirm this claim (Peters et al., Aerospace Med. 34, 830). Independent work is however cited by the author in support of some of her findings which extend to many other groups including alcoholics, smokers, delinquents and subjects receiving analgesics and chlorpromazine.

Experience in the behavioural sciences leads to much wariness in accepting new general hypotheses of the present type and alternative explanations exist for some of the phenomena considered. But if at least part of this hypothesis should stand the test of time it will be a useful contribution to psychology and psychiatry, relevant also to the study of drugs affecting the nervous system.

\section{Shaw's Textbook of Operative Gynaecology}

Revised by JoHn Howkins. Third Edition. Pp. viii +556 illustrated. Edinburgh and London: E. \& S. Livingstone. 1968. $£ 7$.

Beautifully produced and both clearly and lavishly illustrated, this book has, over successive editions, provided aspirants for the Membership examination of the Royal College of Obstetricians and Gynaecologists with a firm and reliable basis for their operative knowledge and the latest edition fully lives up to the reputation earned by its predecessors. Eight years have elapsed since the last edition but, as the author points out in the preface, in a circumscribed speciality such as gynaecology it is unlikely that there will be a large influx of new operative procedures during this period; nevertheless much that has been introduced over the past few years has been incorporated, including new work on construction of the artificial vagina, the use of progestational agents in endometriosis and endometrial carcinoma and the use of cytotoxic drugs in treatment of gynaecological cancer.

Operative Gynaecology has rightly earned high praise and no gynaecological surgeon, whether in training or trained can afford to be unfamiliar with the book; for many, it has become the standard work on operative gynaecology and the one by which other works are judged. It should appear on the library shelves of all hospital libraries and in the personal bookcase of all practising gynaecologists.

Year Book of Pathology and Clinical Pathology 1966-1967 Edited by W. W. Wartman. Pp. 440 illustrated. Chicago: Year Book Medical Publishers. Chichester: John Wiley. 1968. 76s.

The latest in the series of 'Year Books', which have been appearing since 1910, is of the usual format. It consists of selected extended abstracts of important papers published since the last edition, often with apposite editorial comments and references to articles of related or like subjects by Professor William B. Wartman of Northwestern University, Chicago. With very few exceptions, the papers considered are of North American and British origin. This limits its scope, but presumably is intentional. With the large volume of medical literature being poured out today it is impossible to keep abreast even of one's own special subject and these 'Year Books' serve a very useful purpose in not only drawing one's attention to papers one has missed, but also in giving a broad view of advances in all branches of pathology. There are sections on morbid anatomy and histology, haemat- 